\title{
E-Fest 2017 Kicks Off Today
}

\author{
James Beal (EIX.org | e-Fest ${ }^{\circledR}$ | FamilyBusiness.org )
}

KEYWORDS: Entrepreneurship, Startups, student entrepreneurs.

MINNEAPOLIS, April 6, 2017 - Twenty-five finalist teams from universities around the U.S. will begin arriving today for "e-Fest," a competition that will award more than $\$ 200,000$ in grants and scholarships for the best undergraduate business ideas. E-Fest, featuring the final round of judging, an "Innovation Challenge" tomorrow night, workshops and keynote speeches from Best Buy Co. founder Richard M. Schulze and "Shark Tank" TV show regular Daymond John, takes place at the Schulze School of Entrepreneurship (http://www.stthomas.edu/business/schulze-school/) , Opus College of Business, University of St. Thomas.

The finalist teams (see list below) were chosen from a pool of more than 160 teams from 81 schools who submitted seven-minute videos and 12 slides describing their business ideas. A panel of 32 judges selected the finalists, who have received travel stipends and hotel accommodations for the final round.

The largest undergraduates-only business plan competition (as measured by the size of the cash awards), e-Fest is co-sponsored by the Schulze School and by EIX.org(https://eiexchange.com/) , an online learning platform for entrepreneurs, students and professors.

One of these 25 teams will go home with the top prize of $\$ 100,000$ for their business idea. The second- and thirdplace teams will win $\$ 50,000$ and $\$ 25,000$ in prizes. An additional $\$ 10,000, \$ 5,000$ and $\$ 2,500$ in grants will go to their universities to support entrepreneurship education. The Innovation Challenge tomorrow night will award $\$ 20,000, \$ 10,000$ and $\$ 5,000$ in scholarships to the top three student teams that develop the best solution to a business challenge posed that evening.

Below is a list of the finalist business ideas, the students who developed them, their schools and short descriptions of their innovations.

\section{7 e-Fest Finalists}

\section{Boost Linguistics}

Drexel University, Philadelphia, PA

Team: Ethan Bresnahan, Alex Dodson, Jeff Nowak

Advisor: Chuck Sacco

The innovation: Boost Linguistics is a program that uses artificial intelligence to help online content marketers use the best wording for audience engagement.

\section{Caddy-Clean}

Quinnipiac University, Hamden, CT

Team: Joshua Macari, Kyle Freitas

Advisor: Dale Jasinski

The innovation: Caddy-Clean is an all-in-one tool that snaps easily onto a golf cart and can be fetched while on the course to clean off clubs and golf cleats.

\section{Convey Software}

University of Illinois - Urbana Champaign

Team: William Widjaja, Cody Pawlowski

Advisor: Chase Bonhag

The innovation: Convey Software is a tool that analyzes sentiment on social media to predict trends.

\section{Eat Your Coffee}

Northeastern University, Boston, MA

Team: Johnny Fayad, Ali Kothari

Advisor: Kimberly Eddleston

The innovation: "Eat Your Coffee," is a breakfast bar loaded with caffeine for students and others who don't have time to pick up coffee but need their caffeine hit. 


\section{ExpressionMed}

University of St. Thomas, Minneapolis

Team: Meghan Sharkus

Advisor: Laura Dunham

The innovation: ExpressionMed are colorful patches featuring cartoons and friendly designs to help children with diabetes overcome the fear and stigma of using a wearable insulin pump.

\section{FinMoto}

University of St. Thomas, Minneapolis

Team: Sam Rystrom

Advisor: Laura Dunham

The innovation: This is a "virtual financial partner" for young people. Securely linked to their bank accounts, it helps them manage their money, plan for the future, and make intelligent decisions.

\section{GeoSwap}

University of Delaware, Newark, DE

Team: Jason Bamford, Keith Doggett, Jordan Gonzalez

Advisor: Vincent DiFelice

The innovation: GeoSwap is a social media tool described as "Pokemon Go meets Dropbox meets Facebook advertising." Users can look at maps showing the locations of events happening in their area, and add photos showing what they did at each one.

\section{Green Blox}

College of Charleston, Charleston, SC

Team: Joshua Weston

Advisor: Kelly Shaver

The innovation: Green Blox is an eco-friendly, inexpensive building material made from recycled plastic bags and available in a variety of shapes and finishes for many uses in construction.

\section{In Our Hands}

University of Wisconsin - Oshkosh
Team: Abigail Merrill

Advisor: Colleen Merrill

The innovation: In Our Hands is an app that helps citizens be more engaged in the political process and the issues that matter to them

\section{Jacket $\mathbf{3 6 0}$}

Western Michigan University, Kalamazoo, MI

Team: Nicolas Theoret, Brandon Chiddester

Advisor: Lara Hobson

The innovation: Jacket360 is a device, worn on a bicyclist's sleeve, that vibrates when a car is approaching from behind, alerting bicyclists without requiring that they turn around to see the car.

\section{Level Lacrosse - Feeder}

Western Kentucky University, Bowling Green, KY

Team: Muamer Razic

Advisor: Dawn Bolton

The innovation: This device, the size of a pack of gum, helps lacrosse players and coaches monitor individual performance and track their growth. It fits inside the lacrosse stick and feeds into a mobile device, similar to how a FitBit works.

\section{NextStep}

University of New Hampshire, Durham, NH

Team: Sam Warach, TJ Evarts, Max Miller

Advisor: Andrew Earle

The innovation: NextStep is a Software As a Service (SAAS) innovation that connects recovering drug addicts with certified sponsors who can provide mentorship and connect addicts with resources that help them heal.

\section{Orindi Ventures}

Grand Valley State University, Grand Rapids, MI

Team: Jordan Vanderham, Zoe Bruyn

Advisor: Kevin McCurren 
The innovation: The Orindi Mask is a device that helps asthmatics and others with breathing problems who must work outside, by warming the air they breathe.

\section{Park \& Diamond}

Virginia Tech, Blacksburg, VA

Team: David Hall, Jordan Klein

Advisor: Dick Daugherty

The innovation: An attractive, packable bicycle helmet that resembles a baseball cap and gives bicyclists protection without bulk.

\section{PeeWee Packs}

Grove City College, Grove City, PA

Team: Hannah Vaccaro, Ross Harrington

Advisor: Yvonne English

The innovation: PeeWee Packs are flushable wipes that change color and reveal pictures when a toddler uses them in the toilet. The goal is to motivate the toddler to visit the toilet more often and improve potty training.

\section{Phlex-xGoggles}

University of Florida, Gainesville, FL

Team: Luke Torres

Advisor: Michael Morris

The innovation: This wearable device - similar to a glasses frame -- and mobile app helps competitive swimmers and their coaches and teammates track, compare and share their training progress. The device attaches to the swimmer's goggles.

\section{Sensor4Safe}

Seton Hill University, Greensburg, PA

Team: H. Fitzgerald Robertson II, Austin Sheridan, Melanie Ansell, Dhiraj Totwani

Advisor: Lyzona Marshall

The innovation: Sensor4Safety is a device and app designed to reduce the harm to babies and pets accidentally left in vehicles. It monitors movement and temperature in the vehicle and sends messages to the owner's smart phone.

\section{Simplifeye}

NC State University, Raleigh, NC

Team: Cortney Cox

Advisor: Lewis Sheats

The innovation: Simplifeye is a stencil that the user can use on the eyelid while applying liquid eyeliner, for that perfect "cat eye" look.

\section{SpeechMasterPro}

Western Michigan University, Kalamazoo, MI

Team: Daniel Floyd

Advisor: Lara Hobson

The innovation: SpeechmasterPro is a tool, resembling a whistle, that helps people with speech disorders become clearer, more effective speakers.

\section{Strokeflow}

John Hopkins University, Baltimore

Team: Sam Einhorn, Zack Bredl, Emily Hadley, Sofia Diez

Advisor: Phil Phan

The innovation: Strokeflow is a mobile app that allows medical teams to easily track the treatment of stroke patients, as well as amass data that benefits stroke research and patient health. The goal is to improve outcomes, save time and generate better data about what works and what doesn't. The students have told us that it will be tested at JH's medical center this spring.

\section{Tibah}

Binghamton University, Binghamton, NY

Team: David Axelrod, Mauricio Morales

Advisor: Ken Mcleod

The innovation: "Tibah" is a mobile app designed to help fitness enthusiasts stay motivated and trainers keep track of client data.

\section{Torridity Instrument Heating Solutions}




\section{LLC}

University of Wisconsin - Madison, WI

Team: Lizzy Svigelj, Austin Kyle, Zach Klayman

Advisor: Michael Williams

The innovation: Their device prevents sensitive musical instruments from freezing up when they are outside in cold weather, an innovation designed to help student bands and others.

\section{Upright Kids}

University of Wisconsin - Oshkosh

Team: Dylan Parks, Brad Ploch

Advisor: Jordan Rhodes

The innovation: The team has invented an inexpensive, ergonomic standup desk for children to help them be less fidgety in school.

\section{Vowel Inc.}

Babson College, Babson Park, MA

Team: James Cheng, Thomas Lehman

Advisor: Yashiro Yamakawa

The innovation: Vowel Inc. is an app and service that scrutinizes the user's monthly household expenses, looks for less expensive options and actually negotiates with the providers for a better deal.

\section{Yellow Card}

Auburn University, Auburn, AL

Team: Chris Maurice

Advisor: Lakami Baker

The innovation: YellowCard is a digital currency similar to bitcoin, but with many features that make it less challenging to use, especially for those traveling in other countries.

\section{About the e-Fest Speakers}

Dick Schulze founded Best Buy Co. in 1983, and as CEO for 19 years led it to become the dominant consumer electronics retailer in the U.S. The company's 2015 revenue was $\$ 40$ billion. Through the Richard M.
Schulze Family Foundation, Schulze has continued to fund initiatives that support education, human \& social services, and health \& medicine.

Daymond John is a regular of the ABC weekly television show Shark Tank, which received the 2015 and 2014 Emmy Awards for Outstanding Structured Reality Programming. The show features entrepreneurs who present their business concepts to a panel (John, a fashion and branding expert who founded the FUBU clothing company; billionaire Mark Cuban; real estate mogul Barbara Corcoran; Lori Greiner, known as "The Queen of QVC"; tech innovator Robert Herjavec; and venture capitalist Kevin O'Leary). The show is in its eighth season.

Search Terms: Student entrepreneurs, eFest2017, eFest, student innovators, business plans, business ideas 